\title{
Journal of Nursing and Women's Health
}

\section{Evaluation of Prenatal Assistance Based on A Benchmark of Donabedian}

\author{
Maria Helena Gonçalves Jardim ${ }^{1 *}$, Zélia Maria de Sousa Araújo Santos ${ }^{2}$, Italo Rigoberto Cavalcante Andrade ${ }^{3}$ \\ ${ }^{1}$ University of Madeira, Department of Psychology and Health Sciences, Portugal \\ ${ }^{2}$ University of Fortaleza, Department of Nursing, Brazil \\ ${ }^{3}$ University of Fortaleza, Department of Public Health, Brazil
}

"Corresponding author: Maria Helena Gonçalves Jardim, University of Madeira, PhD in Psychology and Health Sciences, Portugal. Tel: +351291209400; Email: hjardim@uma.pt

Citation: Jardim MHG, Santos ZMDSA, Andrade IRC (2017) Evaluation of Prenatal Assistance Based on A Benchmark of Donabedian. J Nurs Womens Health: JNWH-126. DOI:10.29011/JNWH-126. 100026

Received Date: 13 July, 2017; Accepted Date: 02 August, 2017; Published Date: 10 August, 2017

\section{Summary}

Evaluative study of a quantitative approach aiming to evaluate the prenatal care in primary health care under the point of view of pregnancy based on the benchmark of Donabedian. The sample comprised of 195 pregnant women monitored in the prenatal in 20 primary health care units (UAPS) in Fortaleza - Ceará - Brazil. Among pregnant women, 87.7\% were in the age group between 18 and 35 years; 94.4\% attended the elementary and secondary education. On the evaluation of the structure, the pregnant women were dissatisfied. With regard to process, the nurses were available to listen humanized. With regard to the result, $60.5 \%$ of pregnant women were satisfied with the attention received in the primary health care units (UAPS). Therefore, when the operation of UAPS, the interventions and the relationships between users and professionals were adequate, provided greater satisfaction in pregnant women and, consequently, could contribute to the promotion of their health and well-being.

Keywords: Prenatal Care; Performance evaluation; Women's Health

\section{Introduction}

The Prenatal Assistance (APN) is a protective tool for maternal and child health, as it allows the monitoring of pregnancy, guiding and helping to manage certain risk factors, prevent diseases and/or complications, thus creating a bond of trust between the pregnant woman and the professional [1].

In order to improve the quality of APN offered in the country since the confirmation of the pregnancy until the first two years of a baby's life, the Brazilian Government created the Stork Network (Rede Cegonha) [2]. A service of quality in APN holds an important role in reducing maternal mortality, in addition to other benefits for maternal and child health. The Brazil and 10 other Latin American countries have won significant advances in the reduction of deaths related to pregnancy or childbirth of 1990 to 2013. The Brazil reduced its rate of maternal deaths in $43.0 \%$ since the 90. However, the World Health Organization (WHO) warns that none of the countries in the region are able to achieve the goal of the Millennium development goals of reducing maternal mortality rate $75.0 \%$ until 2015 [3].

It is estimated that among the 289,000 maternal deaths for the same complications in 2013, there was a reduction of only $45 \%$ when compared to 523,000 deaths in 1990. Considering the fifth Millennium Development Goal (MDG), only 11 countries have already conquered the 75.0 percent reduction goal (six in Asia, four in Africa and one in Europe- Romania) [3].

In Ceará (CE), the reasons for maternal mortality (MM) presented with decreasing tendency, as in the years 1998 (93.7) 2000 (74.6), stopping in 2001 (73.7), growing in 2002 (87.2), returning to rise in 2004 (88.6) and 2005 (88.5), falling in 2006 (66.7), stationary since 2007 (71.7) until 2010 (79.2), declining in 2011 (67.8), rising in 2012 (90.9) and reaching a small decrease in 2013 (88.6) [4]. The main problems associated with low reduction in $\mathrm{MM}$ are: low access to reproductive planning; low quality of Prenatal $(\mathrm{PN})$; delay in referral to the high-risk PN; lack of active search defaulting to consultations of pregnant women; complications related to pregnancy, childbirth and puerperium; low valuation of complaints and clinical; delay in decision-making 
in the care of complications and urgencies; do not perform the consultation of the puerperium [3].

This reality requires a thorough reflection of managers and health professionals about the conditions under which women give birth to their children and giving birth to come and, mostly, about the quality of care received during the period of pregnancy and child birth in the view of the relevance of the APN for the promotion of maternal health and the concept we ask: how is being held this assistance in the basic attention in Fortaleza-CE? Based on this question, we opted for this study in order to evaluate the prenatal care in primary health care under the point of view of pregnancy based on the benchmark of Donabedian.

Although the evaluation for improving the quality of the family health strategy proposed by the Ministry of health adopts as conceptual reference, the model proposed by Donabedian [5], based on systems theory in which consider themselves the elements of structure, process and result, focusing health services analysis and their practices [6].

\section{Methodology}

Evaluative study with quantitative approach, conducted in 20 Primary Care Health Units (UAPS) located in Regional Executive Secretariat VI in Fortaleza-CE. This secretariat has been chosen because it presents greater scope, among the six, covering the metropolitan region of Fortaleza. The population consisted of 3000 pregnant women who were in the Regional Register in the year 2015. The sample was calculated using the formula for finite population, using the parameters: a) confidence level $95 \%$, sampling error of 6.93 and $\mathrm{p}=0.05$, obtaining a sample of 195 pregnant women.

Included pregnant women in prenatal monitoring, independent of gestational age, who attended at least two nurses and two medical queries, and who have emotional and physical condition to answer questions. Data collection happened during the period from February to May of 2016, through structured interview, whose instrument contained the sociodemographic aspects, and assessment indicators proposed by Donabedian [5], namely:

Structure: Corresponds to relatively stable characteristics and necessary assistance process, and covers-physical area, human resources, Material and financial resources, information systems, regulatory instruments, technical- administrative instruments, organizational conditions.
Process: Is a set of activities developed between professionals and users, consisting of the relationship between these actors, host mode, active listening.

Result: Is the product of the actions, including the satisfaction of pregnant women, motivation for an effective participation, creation and adherence to conduct link, i.e., prenatal care for the prevention and/or control of health risk factors. Note that the instrument was pretested in five pregnant women, but these were not included in the sample. It should be distinguished that the interview was held at UAPS during women's attendance to routine calls and after registering your consent on informed consent. The duration of the interview ranged from 30 to 40 minutes.

The data were organized into the Statistical Package for the Social Sciences (SPSS, version 20.0) and represented in the form of tables and figures. Data were analysed by means of frequencies analysis (Absolute and Relative) and by the following statistical tests: factor analysis, Kaiser-Meyer-Olkin (KMO) and Bartlett's sphericity. Then confronted the data with selected literature and reference Donabedian [5].

This study was carried out in accordance with resolution 466/12, the National Commission of ethics in research (CONEP/ CNS/MS) [7] was submitted and approved by the ethics and Research Committee (CEP) at the University of Fortaleza-UNIFOR, under the Protocol number 11-578.

\section{Results}

Demographic characterization of pregnant women: Most pregnant women were between the ages of 18 and 35 years (87.7\%), brown color (77.4\%), Catholics (56.4\%), domestic (37.9\%), from Fortaleza-CE (95.4\%), living in consensual Union (47.6\%) had attended the elementary and secondary education $(47.2 \%)$, owned homeownership (68.2\%), reporting monthly household income of 1 or 2 minimum wages in force - R\$ $880.00(84.6 \%)$, and resided with the spouse (70.3\%). Evaluation of prenatal Assistance second Donabedian [5].

\section{Structure}

According to Table 1, the majority of pregnant women considered welcoming, the physical structure of the offices $(60.0 \%)$ and sorting $(54.4 \%)$. As to the proper temperature emphasized the nurse's Office $(85.1 \%)$, the doctor's Office $(80.0 \%)$ and sorting $(56.9 \%)$. Only the physical structure of the screening presented statistically significant relationship $(\mathrm{p}=0.010)$. 
Citation: Jardim MHG, Santos ZMDSA, Andrade IRC (2017) Evaluation of Prenatal Assistance Based on A Benchmark of Donabedian. J Nurs Womens Health: JNWH-126.

\begin{tabular}{|c|c|c|c|c|c|}
\hline \multirow[t]{2}{*}{ Assessment Indicators of Physical Structure } & \multicolumn{2}{|c|}{ Yes } & \multicolumn{2}{|c|}{ No } & \multirow[t]{2}{*}{$\mathbf{p}^{*}$ value } \\
\hline & $\mathrm{f}$ & $\%$ & $\mathrm{f}$ & $\%$ & \\
\hline Warm Physical Structure & 117 & 60,0 & 78 & 40,0 & 0,261 \\
\hline \multicolumn{6}{|l|}{ Medical offices Screening } \\
\hline Suitable place to wait & 106 & 54,4 & 88 & 45,1 & 0,010 \\
\hline Proper Temperature & 32 & 16,4 & 163 & 83,6 & 0,075 \\
\hline The doctor's Office & 156 & 80,0 & 39 & 20,0 & 0,094 \\
\hline Nurse's Office & 166 & 85,1 & 29 & 14,9 & 1,050 \\
\hline Screening sector & 111 & 56,9 & 84 & 43,1 & 1,450 \\
\hline The waiting place & 50 & 25,6 & 145 & 74,4 & 1,620 \\
\hline \multicolumn{6}{|c|}{${ }^{*} \mathrm{p}<0,05$ significant } \\
\hline
\end{tabular}

Table 1: Distribution of pregnant women according to satisfaction in relation to the indicators for evaluating the physical structure in APN on UAPS. Fortaleza-Ceará-Brazil, 2016.

In Table 2, in referring to the system of appointments; $96.4 \%$ pregnant women mentioned be at present, $89.2 \%$ by order of arrival, $55.9 \%$ declared that it was every day, $85.1 \%$ said that the range was once a month, $53.3 \%$ reported existence of scheduling priorities according to $87.7 \%$ pregnant women, the duration of the nursing consultation was adequate, and $74.4 \%$, medical consultation was also. About of $64.4 \%$ received information about the functioning of UAPS. Only $33.8 \%$ stated that the professionals were identified with the name and the position on the badge, and $92.3 \%$ reported the existence of the queues to attendance. It should be noted who $76.4 \%$ of pregnant women have stated that it was intended for a week a day on UAPS to be serviced.

Professional identification badge $(\mathrm{p}=0.046)$ and appropriate nursing query duration $(\mathrm{p}=0.049)$ showed statistically significant relationship.

The professionals who attended the pregnant women were predominantly nurses (93.3\%). The reception of the users is performed by staff of the Statistical Medical File System (72.3\%). Although the consultations are scheduled for the three shifts, pregnant women were, preferably, met in the morning.

\begin{tabular}{|c|c|c|}
\hline $\begin{array}{c}\text { Indicators for the evaluation of procedures } \\
\text { for APN }\end{array}$ & $\mathrm{f}$ & $\%$ \\
\hline Query Markup System & & \\
\hline Markup forms - Phone & 1 & 0,5 \\
\hline Attendance & 188 & 96,4 \\
\hline Others1 & 6 & 3,1 \\
\hline Distribution - by order of arrival & 174 & 89,2 \\
\hline Prior scheduling & 21 & 10,8 \\
\hline Periodicity of marking & & \\
\hline Daily & 109 & 55,9 \\
\hline Weekly & 48 & 24,6 \\
\hline Biweekly & 3 & 1,5 \\
\hline
\end{tabular}

\begin{tabular}{|c|c|c|}
\hline Monthly & 35 & 17,9 \\
\hline \multicolumn{3}{|l|}{ Interval between queries } \\
\hline Biweekly & 16 & 8,2 \\
\hline Monthly & 166 & 85,1 \\
\hline Others & 13 & 6,7 \\
\hline Markup Prioritization & 106 & 55,4 \\
\hline Waiting time for marking was appropriate & 50 & 25,6 \\
\hline Appropriate duration of the query - Nursing & 171 & 87,7 \\
\hline Medicine & 145 & 74,4 \\
\hline $\begin{array}{l}\text { Receiving information about the operation } \\
\text { of the services }\end{array}$ & 125 & 64,4 \\
\hline $\begin{array}{l}\text { Professional identification with the name } \\
\text { and the position }\end{array}$ & 66 & 33,8 \\
\hline Existence of the queues to the attendance & 180 & 92,3 \\
\hline
\end{tabular}

Table 2: Distribution of pregnant women according to the indicators for the evaluation of procedures for APN. Fortaleza-Ceará-Brasil, 2015.

\section{Process}

In Table 3, most pregnant women a satisfactory assessment in the work process of the nurse and doctor in all indicators. More indicators answered by women as regards community health Agents: appropriate language (94.1\%); freedom to verbalization (93.4\%); enhancement of verbalization (94.1\%); the user by name $(92.8 \%)$; the existence of dialogue (78.9\%); information from Office holding and name (88.8\%); and providing guidance on preventive ducts (50.8\%). In nursing assistants/Nursing technicians (AE/TE), stood out: appropriate language (77.4\%); freedom to verbalization (62.6\%); and valorization of verbalization (61.5\%). There were statistically significant correlations, the appropriate language $(p=0.022)$, freedom to verbalization $(p=0.036)$, information about the name and title $(\mathrm{p}=0.030)$. Similarly, the name and recipes readable and self-explanatory $(\mathrm{p}=0.026)$ in the nursing 
consultation, preventive therapeutic pipelines $(\mathrm{p}=0.016)$, tests $(\mathrm{p}=0.010)$ and medication $(\mathrm{p}=0.046)$ on medical consultation showed significant correlations.

\begin{tabular}{|c|c|c|c|c|c|c|c|c|c|c|c|c|}
\hline $\begin{array}{c}\text { Evaluation indicators in the work } \\
\text { process of team }\end{array}$ & \multicolumn{3}{|c|}{ Nurses } & \multicolumn{3}{c|}{ Doctors } & \multicolumn{3}{c|}{$\begin{array}{c}\text { Community Health } \\
\text { Agents }\end{array}$} & $\begin{array}{c}\text { Technicians or Nursing } \\
\text { Assistants Assistants }\end{array}$ \\
\hline & $\mathrm{f}$ & $\%$ & $\mathrm{p}$ & $\mathrm{f}$ & $\%$ & $\mathrm{p}$ & $\mathrm{f}$ & $\%$ & $\mathrm{p}$ & $\mathrm{f}$ & $\%$ & $\mathrm{p}$ \\
\hline Appropriate language & 186 & 95,4 & 0,022 & 157 & 80,5 & 0,084 & 143 & 94,1 & 0,032 & 151 & 77,4 & $-0,058$ \\
\hline Freedom for verbalization & 184 & 94,4 & 0,036 & 136 & 69,7 & 0,167 & 142 & 93,4 & 0,015 & 122 & 62,6 & $-0,053$ \\
\hline Appreciation of verbalization & 187 & 95,8 & 0,142 & 140 & 71,8 & 0,248 & 143 & 94,1 & $-0,02$ & 120 & 61,5 & $-0,105$ \\
\hline Approach to user by name & 184 & 94,4 & $-0,107$ & 141 & 72,3 & 0,063 & 141 & 92,8 & $-0,06$ & 81 & 41,5 & 0,043 \\
\hline Existence of dialogue & 169 & 86,7 & $-0,046$ & 118 & 60,5 & 0,059 & 120 & 78,9 & 0,089 & 57 & 29,2 & 0,014 \\
\hline Information: Office and name & 145 & 74,4 & 0,030 & 107 & 54,9 & 0,090 & 135 & 88,8 & 0,017 & 53 & 27,2 & 0,069 \\
\hline \multicolumn{8}{|c|}{ Provision of guidelines } \\
\hline Preventive Ducts & 182 & 93,3 & $-0,006$ & 172 & 88,2 & 0,160 & 99 & 50,8 & 0,069 & 43 & 22,1 & 0,050 \\
\hline Testss & 181 & 92,8 & $-0,143$ & 173 & 88,7 & 0,010 & 68 & 34,9 & 0,065 & 28 & 14,4 & $-0,088$ \\
\hline Medication & 169 & 86,7 & $-0,132$ & 166 & 85,1 & 0,046 & 39 & 20,0 & 0,159 & 15 & 7,7 & 0,115 \\
\hline Absence of discrimination & 193 & 99,0 & 0,022 & 192 & 98,5 & $-0,040$ & & & & & & \\
\hline Easily legible prescriptions & 179 & 91,8 & 0,026 & 127 & 65,1 & 0,113 & & & & & & \\
\hline Prescriptions with generic name & 129 & 66,2 & $-0,033$ & 123 & 63,1 & $-0,070$ & & & & & & \\
\hline
\end{tabular}

Table 3: Distribution of pregnant women according to the indicators of evaluation of the process of work of nurses (E), doctors (M), community health Agents (ACS), technician or nursing assistant (TE/AE). Fortaleza-Ceará-Brazil, 2015.

In the service of the technician or nursing assistant, it was found a statistically significant correlation in the call of the pregnant woman by name $(\mathrm{p}=0.043)$, existence $(\mathrm{p}=0.014)$, guidelines on health condition $(\mathrm{p}=0.050)$, and explanation of the procedures performed $(\mathrm{p}=0.025)$; and for the ACS, appropriate language $(\mathrm{p}$ $=0.032)$, freedom to verbalization $(p=0.015)$ and information Office $(\mathrm{p}=0.017)$.

\section{Result}

Analysing the Table 4, we find that most (60.5\%) of pregnant women were satisfied with the attention received. However, $72.3 \%$ admitted the absence of ties with the Family Health Team (EqSF). Most pregnant women (55.6\%) there was dissatisfaction in attendance held by AE/TE.

\begin{tabular}{|c|c|c|c|c|}
\hline $\begin{array}{c}\text { Assessment Indicators of } \\
\text { Results }\end{array}$ & \multicolumn{2}{|c|}{ Yes } & \multicolumn{2}{c|}{ No } \\
\hline & f & \% & f & $\%$ \\
\hline $\begin{array}{c}\text { Attention received satisfac- } \\
\text { tory }\end{array}$ & 118 & 60,5 & 77 & 39,5 \\
\hline $\begin{array}{c}\text { Existence of link between } \\
\text { user and EqSF }\end{array}$ & 54 & 27,7 & 141 & 72,3 \\
\hline Proper care of the AE/TE & 67 & 44,3 & 84 & 55,6 \\
\hline
\end{tabular}

Table 4: Distribution of pregnant women according to the evaluation indicators the results in APN. Fortaleza-Ceará-Brazil, 2015.

\section{Structure, Process and Result - Factor Analysis}

In Figure 1, according to factor analysis, noted that there was correlation $\beta$, for the following variables based on assumptions:

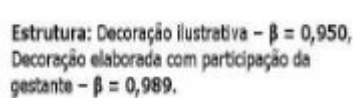

gestante $-\beta=0,989$.
Processo: Consulta médica - Atributos da consulta médica: empatia $-\beta=0,563$, e entusiasmo $-\beta=0,613$; Consulta medica Recebimento de orientaçöes: prognóstico $-\beta=$ 0,564 .

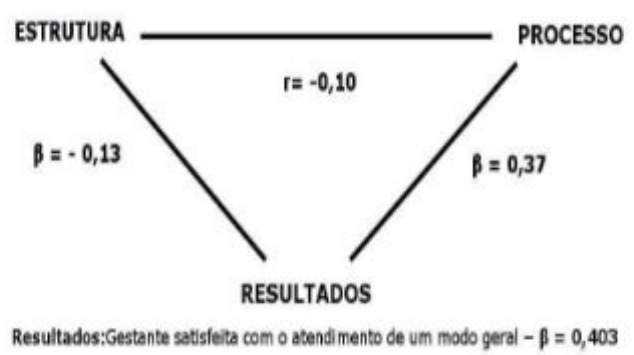

Figure 1: Prenatal evaluation according to the Donabedian constructs. Fortaleza-Ceará-Brazil, 2015.

After individual analysis of each construct of Donabedian (1994), one can infer that the variables selected for the study who composed the Structure did not influence statistically in the Process, demonstrated by $r=-0.10$. On the other hand, the variables selected for the study who composed the Process, influenced statis- 
tically about the Result. What can be observed when met $\beta=0.37$ (Process over Result). To analyse the correlation of the Structure on the result, $\beta=-0.13$, which features a no significant statistical correlation (Structure on Result).

\section{Discussion}

According to Donabedian [5], the structure does mention all attributes, and organizational materials, which are relatively stable in the industry that provides the assistance [6]. According to the data presented, the pregnant women considered the UAPS welcoming offices and sorting service, however dissatisfied with the structural conditions of the waiting room. According to the Ministry of health (MS), the waiting room should be planned so as to provide a comfortable and pleasant, including adjustments of brightness, temperature, noise, positioning of the seats to provide interactAiodnebqeutawt eevnenintidlaivtiodnuailss a(8n).other [8] fundamental aspect in quality care to pregnant women, since this factor is essential to maintain the wholesomeness of UAPS environments. Thus, it is recommended that all environments with Windows or indirect ventilation (exhaust), allowing air circulation [8].

Another difficulty was the absence of a suitable place for carrying out health education activities, requiring improvisation in improper places, without the minimal conditions of comfort needed. This fact was observed in another study conducted in Fortaleza-CE [9]. However, managers recognize the importance of this space [10].

In relation to the process, Donabedian (1994) refers to activities developed by professionals with their clients, as well as the skill with which exert such assistance [11]. These were evaluated according to the organisational aspects, scientific-technical and interpersonal relationship [7].

In organizational terms, it was observed that the UAPS planned attendance of pregnant women for a specific day, the consultations were scheduled for the three shifts, and they were met by professionals of the area assigned, primarily by nurses. Aspects such as planning, implementation, monitoring and evaluation of educative actions in health are fundamental axes of joint activities between the community and health sTerhveicpesre(n6)a.tal [6] consultation is the time that leads to the healthcare plan of specific actions for each woman, according to the physical and psychosocial needs. The adherence and satisfaction of women at prenatal care are related to the quality of care provided by health professionals and services [12].

A study showed the average duration of the nursing consultation in PN that ranged from 15 to 20 minutes in subsequent queries, and 30 minutes on the first-time queries [12]. On the proposal of the study, it is worth mentioning the importance of active listening to this clientele, to provide the information they subsidize a APN of quality, in addition to strengthening the link between pro- fessional and user. The APN must overcome the noise, the communication and the discontinuity of the communicative process, basing its actions on Humanized care [10].

The technical and scientific aspects relating to knowledge, skills and practices of the protocolização health care through actions that aim to ensure the integral health care users, as well as minimize the risks, especially, nature clinical procedures, such as prescription drugs, procedures [6].

According to this study, the Nurse's best runs its activities to meet the needs of health, showing a greater interaction with pregnant women through the reception, listening, and humanized interface provided to the user. The educational actions reduce the asymmetry in the relationship between pregnancy- health services and improve the quality of prenatal care with consequent impact on maternal and child morbidity and mortality, especially in the perinatal period [13].

The host is related directly with the convenience and humanized the deal that the service provides the user, in addition to the operational dimension, of listening to the complaints and health needs, seeking precedent attention through the articulation of the network services. This aspect is fundamental as influences on the level of trust between provider and user, adherence to the indications, continuity in attendance, individual respect, satisfaction of users $[2,6]$. As for interpersonal communication, health outcomes depend largely on the level of information and communication that may exist during the practices. Aspects of relevance relate to information on the health-disease process, health risks, treatment, prognosis, prevention, side effects of medications, minimizing risks and health care [6].

For Donabedia [5], Result corresponds to the consequences of activities in health services, or by the professional, in terms of changes in the State of health of the patients, considering also the changes related to knowledge and behaviour's, as well as the user and worker satisfaction linked to receipt and provision of care [14]. Although, most pregnant women were satisfied with the care received, it should be noted that most of them had no link with the EqSF. However, this leads us to infer that the EqSF still needs to participate more effectively in the NPA, once the process of binding can be considered essential to the quality of care. Pregnant women who have said they are satisfied with the attention received, missed important criteria, such as the absence of effectiveness and efficiency, as describes Donabedian [15].

The factorial analysis provides tools to analyse the structure of correlations between variables or assumptions. Thus, it is concluded that the structure does not have a relevant impact on the process, not the result. However, the process has the greatest impact on the result, perceived by pregnant women.

The use of evaluative processes, understood as critical-reflexive action, developed on the Organization, operation, procedures and working practices of management and service, contributes 
effectively to that managers and professionals have information and acquire necessary knowledge to decision-making aimed at the meeting the demands and health needs, with quality for the scope of the resolution of the systTemhearenfdorues,ertso ' esnathiasfnaccetiothne(6i).nteraction [6] between professional and patient is a primordial aspect of nursing care, and appears as an important step towards the success of the relationship between the two, as it is a fundamental tool to establish a relationship of care and assistance consistent with the needs of every pregnant woman [16].

\section{Conclusion}

\section{From the analysis of the data, it appears that the UAPS performed with a poor structure for prenatal care:}

The physical plant, material resources, the system of appointments, queues, and the care dispensed by EqSF and other employees, demanded a more thorough look, on the part of managers. As for the process, in the opinion of users, $\mathrm{AE} / \mathrm{YOU}$ needed to include dialogue in their professional practice, as well as assist the nurses and doctors in carrying out the educational activities of prevention and damage control/health. It was evidenced that the nurses stood out in the implementation of the educational process, the ACS in setting bond, which is facilitatTedhebfyacthtoerfaenataulyresiosfreitvseacletidvisttiaetsisitnictahlelyctohmatmthueniPtyr.ocess, by opinion of pregnant women, had greater impact on the Result. Therefore, when the operation of UAPS, the interventions and the relationships between users and professionals were adequate, provided greater satisfaction in pregnant women and, consequently, could contribute to the promotion of your health and well-being.

In General, the results of this study may subsidize the (re) planning of actions inherent to APN by the managers and by EqSF, based on assumptions of Donabedian [5]. The quality of the APN is the basis for the promotion of women's health in the gravidpuerperal cycle and of the child, therefore for the reduction of maternal and perinatal morbidity and mortality.

\section{References}

1. Brasil (2012) Ministério da Saúde. Secretaria de Atenção à Saúde. Departamento de Atenção Básica. Atenção ao pré-natal de baixo risco. Brasília: Ministério da Saúde.

2. Brasil (2011) Ministério da Saúde. Secretaria de Atenção à Saúde. Departamento de Atenção Básica. Acolhimento à demanda espontânea. Brasília: Ministério da Saúde.
3. Brasil. Ministério da Saúde. OMS - Brasil reduz mortalidade materna em $43 \%$ de 1990 a 2013.

4. Ceará (2014) Secretaria do Estado de Saúde do Ceará - SESA. Vigilância dos óbitos maternos e implementação dos comitês de prevenção ao óbito materno, infantil e fetal 1-33.

5. Donabedian A (2003) An introduction to quality assurance in health care. New York: Oxford.

6. Brasil (2005) Ministério da Saúde. Secretaria de Atenção à Saúde. Departamento de Atenção Básica. Avaliação para melhoria da qualidade da estratégia saúde da família. Documento Técnico, Brasília: Ministério da Saúde.

7. Brasil (2012) Ministério da Saúde. Resolução № 466, de 12 de dezembro de. Regulamentação da pesquisa envolvendo seres humanos. Brasília: CONEP/CNS/MS

8. Brasil (2008) Ministério da Saúde. Secretaria de Atenção à Saúde. Departamento de Atenção Básica. Manual de estrutura física das unidades básicas de saúde - saúde da família 2. ed. Brasília: Ministério da Saúde (Série A. Normas e Manuais Técnicos).

9. Rocha RS (2011) Atenção pré-natal na rede básica de Fortaleza-CE: uma avaliação da estrutura, do processo e do resultado [Dissertação]. Fortaleza (CE): Universidade Estadual do Ceará.

10. Serapioni M and Silva MGC (2006) Qualidade do Programa Saúde da Família no Ceará. Fortaleza: EdUECE.

11. Rios CTF and Vieira NFC (2007) Ações educativas no pré-natal: reflexão sobre a consulta de enfermagem como um espaço para educação em saúde. Cienc. Saúde colet 12: 477-486.

12. Silva RM, Costa MC, Matsue RY, Sousa GS, Catrib AMF, et al. (2012) Cartografia do cuidado na saúde da gestante. Ciência e Saúde Coletiva 17: 635-642.

13. Ceron MI, Barbieri A, Fonseca LM, Fedosse E (2014) Assistência prénatal na percepção de puérperas provenientes de diferentes serviços de saúde. Rev. CEFAC 19: 815-22

14. Innocenzo MD, Adami NP, Cunha ICKO (2010) O movimento pela qualidade nos serviços de saúde e enfermagem. Rev. Bras. 59: 84-8.

15. Donabedian A (2013) Prioridades para el progresso en la evaluación y monitoreo de la calidad de la atención. Rev Salud Pública 35: 315328.

16. Schmalfuss JM, Prates LA, Azevedo M, Schneider V (2014) Diabetes melito gestacional e as implicações para o cuidado de enfermagem no pré-natal. Rev. Cogitare Enferm 19: 815-22. 